\title{
ANALISIS MEKANISME PEMUNGUTAN DAN PELAPORAN PAJAK PENGHASILAN PASAL 21 UNTUK KARYAWAN DI PT. MARABUNTA ADI PERKASA MANADO
}

\author{
Edgar Gilbert Lumanto $^{1}$, Harijanto Sabijono ${ }^{2}$, Hendrik Gamaliel $^{3}$ \\ ${ }^{1,2,3}$ Jurusan Akuntansi, Fakultas Ekonomi dan Bisnis, Universitas Sam Ratulangi, Jl. Kampus Bahu, Manado, \\ 95115, Indonesia \\ E-mail : mainz05indonesia@yahoo.com
}

\begin{abstract}
Income Tax Article 21 is a tax that is deducted by another party for income in the form of salary, wages, honorarium, allowances, and other payments by name and in any form in connection with work, services, or activities carried out by domestic private taxpayers. On this basis Government Agencies and Companies that pay employees or employees are obliged to apply Article 21 Income Tax calculations to the income received by their employees every month. This research was carried out at PT Marabunta Adi Perkasa Manado. The purpose of the study is to analyze the collection mechanism and Article 21 PPh reporting of PT Marabunta Adi Perkasa Manado whether it is in accordance with the Taxation Law No. 36 of 2008 concerning Income Tax. The research method used in this thesis research is descriptive method whose purpose every data collected is analyzed and then drawn a conclusion and research type used is qualitative descriptive. The research results obtained that the Article 21 PPh collection and reporting mechanism applied by PT Marabunta Adi Perkasa Manado is in accordance with Law No. 36 of 2008 concerning Income Tax.
\end{abstract}

Keywords: Mechanism of Collection, Reporting, Income Tax Article 21.

\section{PENDAHULUAN}

Pajak sangat penting dan gencar-gencarnya dilakukan di negara kita Indonesia. Hal itu dikarenakan banyaknya oknum-oknum yang tidak berhati nurani yang menghindari ataupun tidak membayar pajak dengan benar. Dan juga pajak merupakan salah satu sumber pendapatan negara yang cukup besar di era globalisasi saat ini. Untuk mewujudkan semua itu, pemerintah telah berusaha mensosialisasikan mengenai kesadaran atas peran serta masyarakat sebagai wajib pajak dalam memenuhi kewajiban pajaknya sesuai kutipan dalam Wowor, Sabijono, dan Wokas (2017:770). Dengan pemotong yang benar dan pemungutan yang dilakukan dengan sungguh-sungguh, pendapatan pajak di negara kita bisa maksimal dan optimal. Sungguh disayangkan jika pemungutan pajak di negara kita harus dilakukan pemaksaan apalagi penghindaran pajak karena itu bisa menghambat pembangunan negara kita yang kian pesat dan mendesak ini Dikutip dalam Pangandaheng, Elim, dan Wokas (2017:91) menyebutkan bahwa sumber daya manusia atau pegawai merupakan salah satu faktor pendukung kunci sukses suatu perusahaan. Perusahaan memberikan berbagai fasilitas untuk meningkatkan kualitas kerja pegawai. Selain fasilitas, kesejahteraan pegawai pun perlu diperhatikan agar semakin loyal dalam bekerja. Upaya untuk meningkatkan kesejahteraan pegawai dapat berupa pemberian tunjangan, seperti: tunjangan pajak, tunjangan kesehatan, tunjangan bonus, THR, premi asuransi yang dibayar perusahaan, dan lain-lain. Pemberian bentuk kesejahteraan yang dilakukan perusahaan akan mengakibatkan pengeluaran perusahaan bertambah besar. Bertambah besarnya biaya ini, diharapkan mempunyai pengaruh yang signifikan terhadap kualitas kerja pegawai. 


\section{TINJAUAN PUSTAKA}

Akuntansi. Warren (2015:10) menjelaskan bahwa "secara umum akuntansi dapat didefinisikan sebagai sistem informasi yang menghasilkan laporan kepada pihak-pihak yang berkepentingan mengenai aktivitas ekonomi dan kondisi perusahaan." Wibowo (2013:7) yang merupakan pakar akuntansi Indonesia dalam bukunya, mengemukakan bahwa akuntansi yaitu prosedur mengakui, pencatatan dan korespondensi bursa keuangan dari suatu unsur atau organisasi. Berdasarkan tinjauan pustaka di atas, penulis menyimpulkan bahwa akuntansi yaitu suatu pencatatan semua kegiatan transaksi keuangan dalam suatu perusahaan untuk mempermudah pengambilan keputusan secara cepat dan tepat.

Akuntansi Perpajakan. Akuntansi Perpajakan merupakan aktifitas pencatatan seluruh aktifitas transaksi keuangan yang didalamnya memfokuskan pada perpajakan dan bertujuan untuk menghitung pajak penghasilan ataupun beban pajak terutang dari wajib pajak yang bersangkutan. Menurut Muljono (2013:2) dalam bukunya, menjelaskan bahwa akuntansi perpajakan merupakan bidang yang menjelaskan cara menghitung pajak berlandaskan undang-undang dan peraturan perpajakan.

Pengertian Pajak. Artian yang dikutip Pudihang, Morasa dan Gamaliel (2017:273) menyebutkan bahwa, pajak adalah kewajiban atau sumbangsih kepada negara oleh orang pribadi atau badan yang bersifat memaksa untuk kelangsungan pembangunan negara, yang menuntut untuk kepentingan infrastruktur daerah dan negara.

Sistem Pemungutan Pajak. Sistem pemungutan pajak menurut Sumarsan (2014:14) yang dikutip dalam Gosal, Karamoy, dan Warongan (2017:372) dibagi menjadi:

1. Official Assessment

Sistem pemungutan yakni pemerintah yang berhak menentukan besar pajak yang terutang oleh wajib pajak pribadi

2. Self Assessment

Sistem pemungutan pajak dimana wajib pajak diberi kebebasan untuk menentukan sendiri-sendiri besarnya pajak yang terutang.

3. Withholding

Sistem dimana yang mewenangkan pihak ketiga (dalam hal ini bukan fiskus yang dimaksud), sehingga dapat ditentukan sendiri besarnya pajak terutang.

Pajak Penghasilan. Menurut undang-undang, $\mathrm{PPh}$ pasal 21 yaitu pajak penghasilan yang mencakup pemotongan, penyetoran, dan pelaporan oleh pemotong pajak, dalam hal ini contohnya: pemberi kerja, bendaharawan pemerintah, dana pensiun, badan, perusahaan, dan penyelenggara kegiatan.

Surat Pemberitahuan (SPT). Pengertian SPT adalah surat yang digunakan wajib pajak untuk melaporkan penghitungan dan kewajiban perpajakan sesuai undang-undang.Fungsi surat pemberitahuan:

1. Wadah melapor dan sekaligus bukti tanda penghitungan pajak yang masih harus dibayar.

2. Wadah melaporkan pembayaran atau pelunasan pajak yang telah dilaksanakan sendiri dalam satu tahun pajak atau pada suatu bagian tahun pajak yang ingin dibayar.

3. Pelaporan pembayaran, pemotongan dan pemungutan pribadi atau organisasi lain dalam masa pajak tertentu berdasarkan ketentuan undang-undang.

Penelitian terdahulu. Silalahi (2016) dengan judul Analisa Penghitungan, Pemotongan, Penyetoran, dan Pelaporan Pajak Penghasilan Pasal 21 Pada PT. Bina Swadaya Konsultan Tahun 2016. Hasil penelitian menunjukkan sistem pemotongan Pajak Penghasilan Pasal 21 PT. Bina Swadaya Konsultan menggunakan withholding system dan besarnya potongan belum sesuai dengan undang-undang perpajakan. Yousida (2016) pada tahun yang sama dengan judul Analisis Mekanisme Perhitungan dan Pelaporan PPh 21 Atas Gaji Karyawan PT 
Dafana Surya Medika di Kabupaten Banjar. Hasil penelitian menunjukkan bahwa sistem pelaporan dan perhitungan PPh 21 PT Dafana Surya Medika menggunakan withholding system dan pelaporan pajaknya sudah sesuai dengan undang-undang.

\section{METODE PENELITIAN}

Jenis Penelitian. Jenis penelitian yang penulis gunakan adalah penelitian kualitatif deskriptif. Alasan penulis memilih jenis penelitian ini adalah karena banyak terdapat data deskripsi yang didapat dari narasumber serta berupa bagan dan uraian dan tentunya dapat dipercaya.

Tempat dan Waktu Penelitian. Penelitian dilakukan oleh penulis di PT Marabunta Adi Perkasa Manado yang berada di Marina Plaza Blok B No.22 yang bergerak dalam bidang jasa konstruksi gedung dan bangunan sipil/ kontraktor. Waktu penelitian adalah dari bulan Mei 2018 sampai dengan bulan Agustus 2018.

Metode Pengumpulan data. Jenis data penelitian yang digunakan adalah jenis data kualitatif dan jenis data kuantitatif.Data kualitatif yaitu penelitian yang bersifat deskriptif dan cenderung menggunakan analisis. Data ini berupa penggambaran objek penelitian, data wawancara dengan narasumber, dan informasi sistem pemungutan dan pembayaran $\mathrm{PPh}$ Pasal 21 karyawan perusahaan. Sedangkan data kuantitatif yaitu data numerik yang biasanya menunjukkan pengukuran suatu fenomena tertentu dengan angka. Data ini berupa data gaji pegawai tetap tahun 2018. Adapaun sumber data yang dipakai yaitu data primer. Data Primer adalah data yang diperoleh secara langsung dari objek penelitian dalam hal ini PT Marabunta Adi Perkasa Manado melalui wawancara tatap muka (personal/face to face interviews) dengan Bpk Raymond Yusak Wenas selaku Jab Finance /Accounting Manager PT Marabunta Adi Perkasa Manado.

Teknik Pengumpulan Data. Teknik yang digunakan dalam pengumpulan data yang dibutuhkan dalam penelitian ini yaitu:

1. Dokumentasi, yaitu mengumpulkan data berupa dokumen dan catatan perusahaan yang diperlukan dalam penelitian ini. Teknik pengumpulan data dalam penelitian ini adalah metode dokumenter, teknik ini dilakukan karena data yang dikumpulkan berupa data sekunder yaitu mengumpulkan informasi dari jurnal-jurnal dan buku literatur serta dokumen-dokumen yang terkait dalam hal Pemungutan dan Pelaporan Pajak Penghasilan (PPh) Pasal 21 pada PT Marabunta Adi Perkasa, sebagai sumber data dan acuan dalam penelitian ini. Dokumen-dokumen yang digunakan dalam penelitian ini berupa Surat Setoran Pajak (SSP), sejarah perusahaan, bagan gaji karyawan perusahaan, serta dokumen-dokumen instansi yang terkait.

2. Wawancara, merupakan pengumpulan data yang dilakukan melalui tatap muka maupun tanya jawab langsung yang dilakukan oleh penulis untuk ditanyakan langsung pada narasumber yang bersangkutan.

Metode dan Proses Analisis. Metode analisis penelitian ini diperoleh langsung dari perusahaan yang diteliti. Data- data yang ditemukan dari survei langsung diuraikan melalui analisa guna memperoleh jawaban atas tujuan dari penelitian ini. Berikut ini tahap-tahap untuk menganalisa data:

1. Analisis mekanisme pemungutan dan pelaporan PPh Pasal 21 atas karyawan dari hasil wawancara dengan responden PT Marabunta Adi Perkasa Manado.

2. Membandingkan hasil pemungutan PPh Pasal 21 atas karyawan PT Marabunta Adi Perkasa Manado apakah sesuai dengan ketentuan perpajakan yang berlaku.

3. Membuat kesimpulan beserta saran dari penelitian yang telah diadakan serta perbandingan kewajiban perpajakan perusahaan dan ketentuan perpajakan yang berlaku. 


\section{HASIL ANALISIS DAN PEMBAHASAN}

\subsection{Hasil Analisis}

Analisis Mekanisme Pemungutan dan Pelaporan PPh Pasal 21 oleh PT

Marabunta Adi Perkasa. Berdasarkan hasil penelitian yang dilakukan melalui wawancara, berikut mekanisme pemungutan, pembayaran dan pelaporan PPh Pasal 21 yang dilakukan oleh perusahaan setiap bulannya:

1. Input absensi karyawan yang terkoneksi langsung dengan daftar gaji karyawan di Ms. Excel;

2. Membuat daftar gaji karyawan melalui sistem yang dimiliki perusahaan kemudian dihitung Pajak Penghasilan Pasal 21 seluruh karyawan tetap;

3. Perusahaan membayar gaji seluruh karyawan lewat bank dan PPh 21 masing-masing karyawan langsung ditahan pada saat pengambilan gaji;

4. Buat e-billing;

5. PPh 21 karyawan yang ditahan dikumpulkan kemudian accounting staff menyetor lewat bank/ kantor pos/ atm/ atau lewat internet banking. Penyetoran dilakukan tiap bulan dan pembayaran pada tanggal 1 sampai tgl 10 bulan berikutnya;

6. Dapat bukti penyetoran (NTPN);

7. Input ke aplikasi e-SPT Pasal 21, lalu lapor secara online.

Adapun hasil di atas diperoleh dari hasil wawancara dengan Bpk. Raymond Yusak Wenas, selaku Jab Finance/Accounting Manager PT Marabunta Adi Perkasa Manado, khususnya yang menangani penyetoran pajak. Setelah dilakukan penyetoran pajak, selanjutnya adalah pelaporan pajak. Berdasarkan hasil wawancara, prosedur pelaporan Pajak Penghasilan Pasal 21 karyawan, dilakukan pelaporan SPT secara online melalui e-SPT. Adapun pelaporan SPT dilakukan setiap tahun dan pada bulan April menurut karyawan yang bersangkutan.

Perhitungan Pemungutan Pajak Penghasilan Pasal 21 oleh PT Marabunta Adi Perkasa. Berdasarkan hasil penelitian, perhitungan dan pemungutan $\mathrm{PPh} 21$ ini diperoleh dari penginputan data oleh pegawai bagian keuangan ke aplikasi yang diberikan dari kantor pajak. Berikut adalah mekanisme perhitungan Pajak Penghasilan Pasal 21 oleh PT Marabunta Adi Perkasa Manado:

Tabel 1. Perhitungan PPh 21 PT Marabunta Adi Perkasa Manado Bpk Rafiuddin, K/3

\begin{tabular}{lr}
\hline Gaji Pokok & Rp $\mathbf{1 5 . 0 0 0 . 0 0 0}$ \\
Tunjangan Jabatan & 5.000 .000 \\
PPh & 2.037 .751 \\
BPJS TK & 1.302 .070 \\
Penghasilan bruto sebulan & $\mathbf{2 3 . 3 3 9 . 8 2 1}$ \\
Pengurangan: & \\
Biaya Jabatan 5\% & 500.000 \\
Biaya BPJS TK & 477.035 \\
Penghasilan Netto Sebulan & $\mathbf{2 2 . 3 6 2 . 7 8 6}$ \\
Penghasilan Netto Setahun & 268.353 .435 \\
PTKP & 72.000 .000 \\
Penghasilan Kena Pajak & $\mathbf{1 9 6 . 3 5 3 . 4 3 5}$ \\
Tarif PPh 21 Setahun & 24.453 .015 \\
Tarif PPh 21 Sebulan & $\mathbf{2 . 0 3 7 . 7 5 1}$ \\
\hline Sumber: Daftar
\end{tabular}

Sumber: Daftar Gaji Karyawan Januari 2018 PT Marabunta Adi Perkasa 
Tabel 2. Perhitungan PPh 21 PT Marabunta Adi Perkasa Manado Ibu Cheril, TK/0

\section{Gaji Pokok}

Tunjangan Jabatan

Rp 4.050.000

Tunjangan Harian Lapangan

250.000

(-) Potongan Absen

192.000

BPJS TK

162.000

332.820

Penghasilan bruto sebulan

4.662.820

Pengurangan:

Biaya Jabatan 5\%

Biaya BPJS TK

Penghasilan Netto Sebulan

Penghasilan Netto Setahun

PTKP

Penghasilan Kena Pajak

PPh Pasal 21 Setahun

PPh Pasal 21 Sebulan

Sumber: Daftar Gaji Karyawan Januari 2018 PT Marabunta Adi Perkasa

Pada saat perhitungan Pajak Penghasilan Pasal 21 WP Orang Pribadi, penghasilan anda pada periode pajak selama satu tahun akan dikurangkan dengan total nilai PTKP yang berlaku saat ini.

Tabel 3. PTKP Setahun PT Marabunta Adi Perkasa Manado

\begin{tabular}{llrr}
\hline \multicolumn{1}{c}{ Deskripsi } & Status & \multicolumn{1}{c}{ Nilai } & Total \\
\hline + WP & $\mathrm{WP}$ & 54.000 .000 & 54.000 .000 \\
+ Tanggung 1 & $\mathrm{TK} / 1$ & 4.500 .000 & 58.500 .000 \\
+ Tanggung 2 & $\mathrm{TK} / 2$ & 9.000 .000 & 63.000 .000 \\
+ Tanggung 3 & $\mathrm{TK} / 3$ & 13.500 .000 & 67.500 .000 \\
+ WP Menikah & $\mathrm{K} / 0$ & 4.500 .000 & 58.500 .000 \\
+ Tanggung 1 & $\mathrm{K} / 1$ & 4.500 .000 & 63.000 .000 \\
+ Tanggung 2 & $\mathrm{K} / 2$ & 9.000 .000 & 67.500 .000 \\
+ Tanggung 3 & $\mathrm{K} / 3$ & 13.500 .000 & 72.000 .000 \\
\hline
\end{tabular}

PT Marabunta Adi Perkasa Manado

Biaya jabatan, yaitu 5\% yang dikalikan penghasilan bruto, maksimal Rp 500.000,- sebulan atau $\mathrm{Rp} 6.000 .000$,- pertahun;

Tabel 4. PKP Setahun PT Marabunta Adi Perkasa Manado

\begin{tabular}{rrrr}
\hline Terendah & & Tertinggi & Tarif \\
\hline & 1 & 50.000 .000 & $5 \%$ \\
& 50.000 .001 & 250.000 .000 & $15 \%$ \\
250.000 .001 & 500.000 .000 & $25 \%$ \\
500.000 .001 & (tak terhingga) & $30 \%$ \\
\hline
\end{tabular}

Sumber: PT Marabunta Adi Perkasa Manado

\subsection{Pembahasan}

Penelitian ini membahas tentang analisis mekanisme pemungutan dan pelaporan Pajak Penghasilan Pasal 21 untuk karyawan pada PT Marabunta Adi Perkasa Manado. Data yang diperoleh dengan cara wawancara yaitu data daftar gaji karyawan bulan Januari 2018 PT Marabunta Adi Perkasa Manado. Penghasilan dan gaji yang diterima pegawai pada PT Marabunta Adi Perkasa Manado, didasarkan atas status karyawan, gaji pokok dan tunjangan- 
tunjangan. Perhitungan PPh Pasal 21 atas penghasilan karyawan tetap dengan berdasarkan Undang-Undang Nomor 36 Tahun 2008 diperoleh dengan mekanisme sebagai berikut:

1. Penghasilan Kena Pajak (PKP) dikalikan dengan tarif pasal 17 Undang-Undang Pajak Penghasilan yaitu dikalikan dengan tarif pajak sebesar 5\%;

2. Penghasilan Kena Pajak diperoleh dari penghasilan neto setahun dikurangi dengan PTKP setahun yang diatur dalam Peraturan Menkeu No. 101/PMK.010/2016;

3. Penghasilan neto didapat dari penghasilan bruto kurang 5\% biaya jabatan penghasilan bruto dan iuran pensiun sebanyak $4,75 \%$ dari pokok gaji yang dibayar sendiri oleh karyawan;

4. Penghasilan bruto yaitu gaji pokok ditambah seluruh tunjangan yang diberikan perusahaan.

Dari hasil yang penulis teliti, sistem pemungutan $\mathrm{PPh} 21$ yang dilakukan PT Marabunta Adi Perkasa Manado telah sesuai dengan ketentuan perpajakan yang berlaku dilihat dari gaji pokok, tunjangan jabatan, biaya jabatan sebesar 5\% dari gaji pokok, PTKP, PKP, dan tarif PPh 21 setahun/ sebulan. Sedangkan dalam perhitungan PPh $21 \mathrm{Ibu}$ Cheril, jumlah PTKP lebih besar daripada penghasilan neto setahun karyawan. Sehingga jumlah $\mathrm{PPh}$ 21, baik yang dilakukan oleh PT Marabunta Adi Perkasa Manado adalah nihil. Dengan kata lain, karyawan tidak memiliki tanggungan untuk membayar pajak. PTKP yang digunakan sebagai pengurang penghasilan neto dalam perhitungan Pajak Penghasilan Pasal 21 karyawan yang dikutip Rondonuwu, Elim, dan Pinatik (2017:49) yaitu Rp 54.000.000,00 (lima puluh empat juta rupiah) untuk diri wajib pajak orang pribadi, dan Rp 4.500.000,00 (empat juta lima ratus ribu rupiah) tambahan untuk wajib pajak yang kawin serta $R p$ 4.500.000,00 (empat juta lima ratus ribu rupiah) tambahan untuk setiap anggota keluarga yang ditanggung sepenuhnya, maksimal 3 orang pada setiap keluarga wajib pajak.

Perhitungan tarif PPh 21 atas gaji karyawan PT Marabunta Adi Perkasa Manado, dilakukan dengan menggunakan bantuan komputer yang akan menghitung jumlah $\mathrm{PPh} 21$ karyawan berdasarkan data rekap gaji dan absensi karyawan. Adapun penggunaan komputer yaitu aplikasi yang diberikan dari kantor pajak kepada PT Marabunta Adi Perkasa Manado. Berikut ini mekanisme pembayaran dan pelaporan $\mathrm{PPh} 21$ yang penultis teliti sebagai berikut:

1. Mekanisme dan tatacara perhitungan pajak telah menngadopsi sistem milik perusahaan yang otomatis terpotong dengan sendirinya. Layanan aplikasi ini merupakan perhitungan gaji karyawan PT Marabunta Adi Perkasa Manado.

2. Proses penyetoran tarif $\mathrm{PPh} 21$ yakni melalui bank yang kemudian langsung ditransfer ke kas negara. Penyetoran pajak dilakukan tiap bulan pada tanggal 1 sampai tgl 10 bulan berikutnya. Accounting staff akan dikenai sanksi jika bersikap lalai dalam penyetoran.

3. Pelaporan tarif PPh 21 karyawan PT Marabunta Adi Perkasa Manado, dilakukan oleh accounting staff, yaitu dengan cara menyampaikan SPT Tahunan secara elektronik (eSPT). Dan pelaporan pajak oleh accounting dilakukan pada bulan Maret setelah berakhirnya tahun pajak. Pengisian e-SPT oleh pegawai, berdasarkan pada sistem perhitungan gaji karyawan yang dibuat oleh divisi HRD / personalia.

Berdasarkan proses pemungutan PPh Pasal 21 karyawan PT Marabunta Adi Perkasa Manado telah berjalan sesuai prosedur dan peraturan-peraturan yang berlaku. Pemungutan Pajak Penghasilan Pasal 21 yang menggunakan sistem sudah efektif dan efisien, serta proses pembayaran dan pelaporan yang dilakukan setiap bulan yang kemudian disetorkan ke bank untuk disetorkan ke kas negara. 


\section{KESIMPULAN DAN SARAN}

\subsection{Kesimpulan}

Berdasarkan pembahasan dan analisis mengenai mekanisme pemungutan dan pelaporan Pajak Penghasilan Pasal 21 untuk karyawan di PT Marabunta Adi Perkasa Manado, maka pada bab terakhir ini diambil kesimpulan sebagai berikut:

1. Sistem pemungutan PPh Pasal 21 yang dilakukan PT Marabunta Adi Perkasa Manado telah cocok, sama dan sesuai dengan undang-undang.

2. Berdasarkan penghitungan perusahaan tentang penerapan nilai PTKP, PKP, biaya menjabat, dan tarif pajak penghasilan yang ditentukan oleh PT Marabunta Adi Perkasa Manado kepada karyawannya telah tepat dan sesuai.

3. Hasil setor rutin PPh 21 masa pegawai pada PT Marabunta Adi Perkasa Manado dilakukan oleh accounting staff sebelum tanggal 10 bulan berikutnya, dan sesuai dengan batas waktu yang ditetapkan.

4. Pelaporan PPh 21 wajib pajak orang pribadi oleh karyawan PT Marabunta Adi Perkasa Manado, dilakukan melalui e-filling paling lama akhir bulan April. Sebagaimana belum sesuai dengan peraturan perpajakan yaitu akhir bulan Maret.

\subsection{Saran}

Sesuai dengan hasil penelitian pada bab-bab sebelumnya, saran penulis kepada perusahaan yaitu mengharuskan seluruh karyawan tetapnya memiliki NPWP agar terjadi penghematan dan lebih efisien dalam memungut $\mathrm{PPh} 21$ terutang dan pelaporan $\mathrm{PPh} 21$ oleh karyawan pada PT Marabunta Adi Perkasa Manado, harus dapat melaporkan e-filling sebelum akhir bulan Maret agar tidak dikenai denda atau sanksi administrasi

\section{DAFTAR PUSTAKA}

Hardianto, Aloysius Taufan. 2012. Mekanisme Perhitungan dan Pelaporan Pajak Penghasilan (PPH) Pasal 21 Karyawan (Studi Pada PT.Dutacipta Pakarperkasa Surabaya). Skripsi. Universitas Brawijaya. Malang.

Malia, Evi. 2016. Penerapan Akuntansi Untuk Pajak Penghasilan (PPh) Pasal 21 Pada Puskesmas Palengaan Pamekasan. Skripsi. Universitas Islam. Madura.

Mawarni, Rizqi Arum. 2015. Analisis Sistem dan Prosedur Pembayaran Pajak Penghasilan Pasal 21 Pada Pegawai Negeri Sipil (Studi Pada Rumah Sakit Ngudi Waluyo Wlingi). Skripsi. Universitas Brawijaya. Malang.

Nugraheni, Berlian Paramita. 2012. Analisis Mekanisme Pencairan Gaji sampai Pengenaan Pajak Penghasilan Pasal 21 atas Gaji Pegawai Negeri Sipil. Skripsi. Universitas Sebelas Maret. Surakarta.

Pangandaheng, V. Elim, I. dan Wokas, H. 2017. Analisis Perhitungan PPh Pasal 21 Terhadap Pegawai Tetap Atas Berlakunya PMK RI No:101/PMK.010/2016 Tentang PTKP Studi Kasus Pada PT. Bank Sulut Go Cabang Tahuna. Jurnal Riset Akuntansi Going Concern Vol. 12 No. 2. Universitas Sam Ratulangi.

Ramli, M Irvan. 2014. Analisis Perhitungan PPh Pasal 21 Karyawan Tetap PT Asuransi Adira Dinamika Outlet Jambi. Skripsi. Politeknik Negeri Sriwijaya. Palembang.

Republik Indonesia. Undang-Undang Nomor 28 tahun 2007: Tentang Perubahan Ketiga atas UU RI No. 6 Tahun 1983 tentang Ketentuan Umum dan Tata Cara Perpajakan.

Republik Indonesia. Undang-Undang Nomor 36 tahun 2008: Tentang Perubahan Keempat atas UU RI No. 7 Tahun 1983 tentang Pajak Penghasilan.

Tumbel, A. Karamoy, H. dan Tirayoh, V. 2017. Evaluasi Mekanisme Pemotongan Dan Pelaporan Pajak Oleh Bendaharawan Pemerintah Pada Badan Perencanaan Penelitian Dan Pembangunan Kabupaten Minahasa Selatan. Jurnal Riset Akuntansi Going Concern Vol. 12 No. 2. Universitas Sam Ratulangi 
Silalahi, Evi Margoretty. 2016. Analisis Mekanisme Penghitungan, Pemotongan, Penyetoran dan Pelaporan Pajak Penghasilan Pasal 21 Pada PT. Bina Swadaya Konsultan Tahun 2016. Skripsi. Universitas Mercu Buana. Jakarta.

Wowor, V. Sabijono, H. dan Wokas, H. 2017. Pengaruh Sikap Wajib Pajak Terhadap Kepatuhan Wajib Pajak Bumi dan Bangunan (PBB) di Kecamatan Motoling di Kabupaten Minahasa Selatan. Jurnal Riset Akuntansi Going Concern Vol. 12 No. 2. Universitas Sam Ratulangi.

Yousida, Imawati. 2016. Analisis Prosedur Perhitungan dan Pelaporan Pajak Penghasilan Pasal 21 Atas Gaji Karyawan PT Dafana Surya Medika di Kabupaten Banjar. Skripsi. STIE Pancasetia. Banjarmasin. 